\title{
1 Linking drugs of abuse in wastewater to contamination of surface and drinking water
}

3 Angela Rodayan ${ }^{\dagger}$, Shadi Afana ${ }^{\dagger}$, Pedro Alejandro Segura ${ }^{\dagger}$, Tamanna Sultana $^{\ddagger}$,

4 Chris D. Metcalfe ${ }^{\ddagger}$, Viviane Yargeau ${ }^{\dagger^{*}}$

${ }^{\dagger}$ Department of Chemical Engineering, McGill University, Montreal, QC, Canada

$7 \quad{ }^{\ddagger}$ Water Quality Centre, Trent University, Peterborough, ON, Canada

$9 *$ Address correspondence to viviane.yargeau@mcgill.ca

\section{Abstract}

The concentrations of 17 drugs of abuse (DOAs), including cocaine, several amphetamine,

13 opioid drugs and two metabolites, benzoylecgonine (BE) a metabolite of cocaine and 2-

14 Ethylidene-1,5-Dimethyl-3,3-Diphenylpyrolidine (EDDP) a metabolite of methadone, were

15 investigated in an urban watershed that is heavily impacted by discharges of municipal

16 wastewater. The artificial sweetener, sucralose was also monitored as a persistent tracer of

17 contamination from municipal wastewater. Monitoring was conducted in a municipal wastewater

18 treatment plant (WWTP) and at sites upstream and downstream of the WWTP discharge, as well

19 as in a drinking water treatment plant (DWTP) located $19 \mathrm{~km}$ downstream of the WWTP

20 discharge that withdraws raw water from the river. Drug concentrations were monitored with

21 Polar Organic Chemical Integrative Samplers (POCIS) deployed for 2 weeks in the river and in

22 the WWTP and DWTP. Several of the investigated compounds exhibited a decrease in

23 concentration with distance downstream from the wastewater discharge into the river, but there

24 was little attenuation of sucralose, cocaine, BE, morphine, acetylmorphine (a-morphine),

Rodayan, A., Afana, S., Segura, P.A., Sultana, T., Metcalfe, C., Yargeau, V., Linking drugs of abuse in wastewater to contamination of surface and drinking water, Environmental Toxicology and Chemistry, Volume 35, Issue 4, 843-849 (April 2016) 
acetylcodeine (a-codeine) and oxycodone. Heroin and methadone were not detected at any sample locations. Amphetamine (AMP), methamphetamine (METH), 3,4-methylenedioxy-

27 methamphetamine (MDMA), and EDDP were not detected in the samples collected at the

28 drinking water intake. Many of the DOAs were not removed effectively in the DWTP, including

29 cocaine, BE, methylenedioxyamphetamine (MDA), ephedrine, and several prescription opioids,

30 most probably because the DWTP was operating at or above its rated treatment capacity. These

31 data indicate that there can be transport of DOAs from wastewater sources into drinking water in 32 urban watersheds.

34 Keywords: Cocaine, amphetamines, opioids, POCIS, drugs of abuse

\section{INTRODUCTION}

Drugs of abuse (DOAs), including both illicit drugs and prescription drugs are contaminants of emerging concern (CECs) that have been detected in wastewater and surface waters [1]. After excretion as either the parent compound or as metabolites, these classes of

40 drugs make their way to wastewater treatment plants (WWTPs). Many studies have investigated

41 the presence of DOAs in wastewater and it is clear that many of these compounds are not

42 completely removed during conventional wastewater treatment and that they are released into

43 surface waters via effluent discharges [2-9]. DOAs have potent biological activities and they may

44 impact aquatic organisms, either alone or as mixtures with other pharmaceuticals [10, 11].

45 Pharmaceuticals can be transformed through biological, chemical or photochemical processes or 46 can be adsorbed, depending on the nature of the compound $[12,13]$. In areas where surface

Rodayan, A., Afana, S., Segura, P.A., Sultana, T., Metcalfe, C., Yargeau, V., Linking drugs of abuse in wastewater to contamination of surface and drinking water, Environmental Toxicology and Chemistry, Volume 35, Issue 4, 843-849 (April 2016) 
47 waters are used as sources of drinking water, DOAs may also contaminate drinking water [14,

48 15]. Wastewater reuse is becoming more common and there is concern about the presence of

49 DOAs in water supplies [16].

Since concentrations of CECs in the aquatic environment are subject to large temporal

52 variations, passive sampling has been used to provide estimates of the time weighted average

53 (TWA) concentrations of compounds over several days or weeks of sampler deployment [17].

54 The Polar Organic Chemical Integrative Sampler (POCIS) was developed by Alvarez et al. [18]

55 to sequester hydrophilic organic chemicals from aquatic matrices, and TWA concentrations can

56 be calculated using sampling rates $\left(\mathrm{R}_{\mathrm{S}}\right.$ in $\left.\mathrm{L} \mathrm{d}^{-1}\right)$ measured experimentally for each target analyte.

57 POCIS have been shown to be effective at sampling pharmaceuticals and pesticides from water

$58[19,20]$ but relatively few studies have used POCIS to estimate the concentrations of DOAs in

59 water and wastewater [16, 21-23].

The objective of this study was to evaluate the transport of DOAs from wastewater to

62 drinking water in an urban watershed. A range of DOAs, including cocaine and its primary

63 metabolite (BE), EDDP a metabolite of methadone, amphetamines and opioid compounds were

64 monitored as they were transported through a WWTP, carried downstream in a river from the

65 point of wastewater discharge, and subsequently taken up and treated in a downstream drinking

66 water treatment plant (DWTP). The study area was the Grand River in southern Ontario, Canada,

67 which receives effluents from several municipal WWTPs, and also serves as a source of drinking

68 water for several communities $[24,25]$. Our hypothesis is that these compounds are persistent

Rodayan, A., Afana, S., Segura, P.A., Sultana, T., Metcalfe, C., Yargeau, V., Linking drugs of abuse in wastewater to contamination of surface and drinking water, Environmental Toxicology and Chemistry, Volume 35, Issue 4, 843-849 (April 2016) 
enough in aquatic systems and may potentially impact the quality of drinking water. To test this

70 hypothesis, we compared the concentrations of DOAs to the concentrations of an artificial

71 sweetener, sucralose that is known to be a persistent tracer of wastewater contamination [26, 27]

72 and has been detected previously at high concentrations in the Grand River [28].

\section{MATERIALS AND METHODS}

2.1 Chemicals, reagents and supplies

Analytical standards of all DOAs and their deuterated analogs (list of compounds provided

in the Supplemental Data, Table S1) were obtained from Cerilliant at a purity higher than 99\%.

78 Sucralose and its deuterated surrogate were purchased from Sigma-Aldrich and Toronto

79 Research Chemicals, respectively. Stock solutions were made up in methanol and stored in the

80 refrigerator $\left(4^{0} \mathrm{C}\right)$ until required. Working standard solutions were prepared from stock solutions

81 through serial dilution.

HPLC or equivalent grades of methanol, acetone, acetonitrile, ACS reagent grade dichloromethane (DCM), hydrochloride acid (37\%), sulphuric acid (96\%), formic acid (88\%),

85 and trace metal grade ammonium hydroxide (88\%) and sodium sulfate were purchased from

86 Fisher Scientific. Optima grade methanol, acetonitrile, and water were also purchased from

87 Fisher Scientific. All other water was obtained from a Milli-Q water purification system

88 purchased from Millipore. Whatman $1.5 \mu \mathrm{m}$ glass microfiber filters were purchased from Fisher

89 Scientific. Oasis MCX cation exchange cartridges $(6 \mathrm{~mL} / 150 \mathrm{mg})$ were purchased from Waters

Rodayan, A., Afana, S., Segura, P.A., Sultana, T., Metcalfe, C., Yargeau, V., Linking drugs of abuse in wastewater to contamination of surface and drinking water, Environmental Toxicology and Chemistry, Volume 35, Issue 4, 843-849 (April 2016) 
90 Corporation. Pharmaceutical POCIS containing Oasis HLB (200 mg) sequestration medium were

91 purchased from Environmental Sampling Technologies.

POCIS samplers were deployed over a two week period from July 10-24, 2012 at locations

95 in the Grand River watershed in southern, Ontario, Canada. POCIS monitoring was conducted at

96 a WWTP in the treated wastewater stream, at sites in the Grand River upstream (2 locations) and

97 downstream (3 locations) of the WWTP discharge, and in the raw and treated water streams of a

98 DWTP that uses the river as a source of water. POCIS ( $\mathrm{n}=3$ per location) were deployed on July

9910 and retrieved two weeks later. Grab samples were collected in 1 L pre-cleaned amber glass

100 bottles on the days of POCIS deployment and retrieval in order to compare the concentrations of

101 target compounds detected using both methods. The WWTP treats wastewater for an urban

102 population of approximately 94,000 using conventional activated sludge treatment and has a

103 maximum flow capacity of $81,800 \mathrm{~m}^{3} \mathrm{~d}^{-1}$. Surface water samples were collected and POCIS were

104 deployed in the Grand River at two points approximately $2 \mathrm{~km}$ apart located upstream of the

105 WWTP discharge and at three downstream sites approximately $40 \mathrm{~m}$ downstream of the

106 discharge, and at $10 \mathrm{~km}$ and $18 \mathrm{~km}$ further downstream. The furthest downstream site was only

$10720 \mathrm{~m}$ from the intake for the DWTP. The small DWTP serves a population of approximately

1081,800 people and the design flow is $1.6 \times 10^{6} \mathrm{~L} \mathrm{~d}^{-1}$. The plant uses a limited treatment train

109 consisting of coagulation, flocculation, filtration and chlorine disinfection. POCIS were deployed

110 in the treatment stream for both raw and treated drinking water. 
POCIS samplers were kept in air-tight canisters prior to deployment. A total of 6 POCIS

113 were deployed at each site in a stainless steel sampling cage; three POCIS for monitoring DOAs

114 and three POCIS for monitoring sucralose. POCIS field blanks were exposed to ambient air

115 during the deployment and retrieval of the POCIS samplers. Upon retrieval, each POCIS disk

116 was individually wrapped in aluminum foil and stored in a sealable plastic bag and placed on ice

117 during transportation. Following collection, samples were stored in a cooler at $4^{\circ} \mathrm{C}$ for transport

118 to the laboratory, where they were then stored at $-20^{\circ} \mathrm{C}$ until extraction, which was carried out

119 within one month of collection.

\subsection{Extraction}

POCIS samplers were extracted according to methods previously described by Li et al.

123 [29]. Briefly, frozen samplers were removed from storage and allowed to thaw, then rinsed with

124 water to remove debris and biofouling material. The sorbent in the POCIS was transferred

125 manually to a glass chromatography column previously packed to $1 / 3$ full with granular $\mathrm{Na}_{2} \mathrm{SO}_{4}$.

126 Deuteurated analogs were then added to the column as surrogates. Elution from the column was

127 performed with $100 \mathrm{~mL}$ methanol. After evaporation, the samples were made up to their final

128 volume $(0.4 \mathrm{~mL})$ with methanol. The DOAs and sucralose were sampled in individual POCIS

129 that were extracted separately. Extraction efficiencies of all compounds in the three matrices

130 were $>80 \%$ (Supplemental Data, Table S1).

Grab samples were extracted in triplicate by solid phase extraction (SPE) with Oasis MCX

133 cartridges using previously developed methods. The DOAs and sucralose were extracted

Rodayan, A., Afana, S., Segura, P.A., Sultana, T., Metcalfe, C., Yargeau, V., Linking drugs of abuse in 
134 separately using two different methods. Prior to SPE, all aqueous samples were vacuum filtered 135 through $1.5 \mu \mathrm{m}$ glass fibre filters. For untreated wastewater samples, $100 \mathrm{~mL}$ volumes were

136 filtered, whereas for treated wastewater, surface water, raw and treated drinking water samples, a 137 volume of $200 \mathrm{~mL}$ was used. All samples were acidified to a $\mathrm{pH}$ of $2.5 \mathrm{using} 3.5 \mathrm{M}$ sulphuric 138 acid and then spiked with $100 \mu \mathrm{L}$ of $500 \mathrm{ng} \mathrm{mL}^{-1}$ surrogate standard mixture. For DOAs, SPE 139 was carried out using a Gilson GX-271 ASPEC $^{\mathrm{TM}}$ automated extraction system. The extraction 140 method was based on our previously published method for illicit drugs [25] that was modified to

141 include opioid drugs [22]. Sucralose was extracted by SPE using the manual SPE method

142 previously described by [30]. Extracts were evaporated and reconstituted to a volume of $0.4 \mathrm{~mL}$

143 in $25 \%$ water $/ 75 \%$ methanol. SPE recoveries for all compounds in each of the three matrices

144 were $>80 \%$ (Supplemental Data, Table S1).

\subsection{POCIS sampling rates}

Sampling rates (Rs) for the most DOA target compounds were previously reported by Yargeau et al. [22] and are listed in the Supplemental Data, Table S1. Note that $\mathrm{R}_{\mathrm{s}}$ values for

149 acetylcodeine, acetylmorphine and heroin could not be determined, which is probably due to the

150 highly polar nature of these compounds [22]. The sampling rate for sucralose was previously

151 described by Metcalfe et al. [30]. The POCIS sampling rates for ketamine $\left(0.197 \pm 0.007 \mathrm{Ld}^{-1}\right)$

152 and fentanyl $\left(0.390 \pm 0.051 \mathrm{Ld}^{-1}\right)$ are reported here for the first time.

The sampling rates $\left(\mathrm{R}_{\mathrm{s}}\right)$ were determined as previously described by Li et al. [29] using

154 bench scale experiments with static exposure conditions where the decrease in concentration of 155 the compounds in water was monitored over time. Briefly, the static experiments were 
156 conducted in triplicate in containers with $3 \mathrm{~L}$ of water placed in a temperature controlled

157 environmental chamber at $25^{\circ} \mathrm{C}$. For each replicate, the water was spiked with the compounds of

158 interest at a nominal concentration of $3 \mu \mathrm{g} \mathrm{L}^{-1}$ and a single POCIS was placed in the water for a

159 period of 3 days. A magnetic stirrer was used to gently mix the water. Aliquots of the exposure

160 water $(40 \mathrm{~mL})$ were removed from the bottles every $24 \mathrm{~h}$ to monitor the decrease in water

161 concentration over time. The water was extracted by SPE according to the methods described

162 above. Control experiments containing only fortified water without the POCIS (i.e. positive

163 control) were run along with the calibration to correct for sorption, volatilization or degradation

164 during exposure. As a negative control, one POCIS was exposed to $3 \mathrm{~L}$ of water without spiking

165 of pharmaceuticals. The $\mathrm{R}_{\mathrm{s}}$ of the POCIS was calculated from the slope of the line describing the

166 decline in concentration over time. As in previous experiments to determine sampling rates with

167 this static exposure method [19,29], the sampling rates were confirmed by comparing estimates

168 of the mass of the target compounds accumulated on the sorbent over the 3 day experiment to the

169 measured mass of the compound extracted from the POCIS at the end of the experiment. The

170 estimates of the mass accumulated on the POCIS over time, $\mathrm{m}_{\mathrm{s}}(\mathrm{t})$ were determined by

171 rearranging the equation presented by Allan et al. [32] to yield:

$$
m_{s}(t)=m_{s}(0)+C_{w} R_{s} t
$$

Where: The amount of the analyte on the sorbent at time $0, \mathrm{~m}_{\mathrm{s}}(0)$, which was determined

174 from control experiments to be zero, $C_{w}$ is the initial concentration in the water, $R_{s}$ is the 175 estimated sampling rate, and $t=3$ days. These data for fentanyl and ketamine are illustrated in

176 Supplemental Data, Figure S1. The results indicate good agreement between the estimated and 177 measured amounts of the target compounds retained by the POCIS sorbent. Further, these data

Rodayan, A., Afana, S., Segura, P.A., Sultana, T., Metcalfe, C., Yargeau, V., Linking drugs of abuse in 
178 indicate that the amounts of the target compounds retained by the POCIS membrane (not

179 extracted) are negligible relative to the amount retained by the solid sorbent.

\subsection{Analysis}

The concentrations of DOAs were measured by liquid chromatography with high

182 resolution mass spectrometry (LC-HRMS) using an Accela LC system coupled to a hybrid linear

183 ion trap-orbital trap instrument, LTQ Orbitrap XL (Thermo Fisher Scientific, Waltham, MA).

184 Chromatographic separation of the target compounds was achieved using a Hypersil Gold

185 column $(50 \times 2.1 \mathrm{~mm}, 1.9 \mu \mathrm{m})$ with an in-line Direct-Connection UHPLC $0.2 \mu \mathrm{m}$ filter held at a

186 temperature of $30^{\circ} \mathrm{C}$. An optimized gradient of methanol in water (solvent A) and acetonitrile

187 (Solvent B) both with $0.1 \%$ acetic acid at a flow of $0.3 \mathrm{mLmin}^{-1}$ was used. The percentage of

188 organic (B) was changed as follows: $0 \mathrm{~min}(10 \%), 1.75 \min (10 \%), 3.05 \mathrm{~min}(25 \%), 5.55 \mathrm{~min}$

189 (97\%), $7.55 \min (97 \%), 7.75 \min (10 \%), 16.00 \min (10 \%)$. Ionization was done in positive mode

190 using a heated electrospray ionization (HESI) source with the following parameters: sheath gas

191 flow $=45$ arbitrary units, auxiliary sheath gas flow $=10$ arbitrary units, capillary temperature $=$

$192375^{\circ} \mathrm{C}$, capillary voltage $=5 \mathrm{~V}$, tube lens $=100 \mathrm{~V}$. Acquisition was performed in full scan mode

$193(\mathrm{~m} / \mathrm{z} 50-400)$ at high resolution $\left(R_{\mathrm{FWHM}}=41000\right)$ and analyte quantification was carried out by

194 extracting the ion of interest from the orbital trap total ion current chromatogram using an $\mathrm{m} / \mathrm{z}$

195 window of \pm 0.01 . Confirmation of the presence of the target analyte was done by collision-

196 induced mass spectra using a data dependent tandem mass spectrometry experiment in the linear

197 ion trap portion of the instrument. Quantification was done using an eight-point calibration curve 198 generated for each compound in the range of 3 to $150 \mu \mathrm{g} \mathrm{L}^{-1}$, corresponding to the range of

199 concentration obtained after preconcentration, as well as the linear correlation coefficients. The

Rodayan, A., Afana, S., Segura, P.A., Sultana, T., Metcalfe, C., Yargeau, V., Linking drugs of abuse in 
deuterated stable isotope surrogates were used as internal standards at a constant concentration of

$201100 \mu \mathrm{g} \mathrm{L}^{-1}$ to correct for mass losses during sample preparation, as well as matrix effects during

202 analysis.

203

204

Analysis of sucralose was conducted by LC coupled with tandem mass spectrometry (LC-

205 MS/MS) in negative ion mode using an AB Sciex Q-Trap 5500 instrument with a turbospray

206 ionization source, and equipped with an Agilent 1100 series (Mississauga, ON, Canada)

207 separation system. Sucralose was separated chromatographically using a Genesis C-18 column

208 and a guard column of the same stationary phase (Chromatographic Specialties, Brockville, ON,

209 Canada). The LC mobile phases for gradient elution were described previously by Metcalfe et al.

210 [30]. Multiple reaction monitoring (MRM) was performed using the precursor and product ion

211 transitions of $395 \rightarrow 359$ and $395 \rightarrow 35$ for sucralose, and $403 \rightarrow 367$ and $403 \rightarrow 35$ for the

212 corresponding labelled surrogate, sucralose-d6. An external standard method with a five-point

213 calibration curve was used for quantification, and the data were adjusted according to response

214 for the surrogate internal standard.

\subsection{Method validation}

216 The limits of detection (LODs) and limits of quantification (LOQs) for the target

217 compounds in wastewater, surface water and drinking water were defined as the analyte

218 concentration that produced a peak with a signal to noise ratio of 3 and 10, respectively. All

219 method validation was done using spiked samples of each matrix. The LODs and LOQs of the

220 target compounds in each matrix are listed in the Supplemental Data, Table S2. The repeatability

221 between runs on the same day and between days was always $<15 \%$. Quality control samples in 
222 each matrix were included in sample runs and the relative error between the measured

223 concentration and the expected concentration was always $<20 \%$ for all target compounds. Field

224 blank POCIS were processed exactly as described for the deployed POCIS and none of these

225 samples contained residues of the analytes at levels above the limits of detection.

\section{RESULTS AND DISCUSSION}

\subsection{Overview of the results}

The concentrations of the analytes in the Grand River at sites upstream and downstream of

230 the WWTP discharge, as well as the concentrations in treated wastewater in the WWTP and in

231 raw and treated drinking water in the DWTP are summarized in Figure 1. These data are the

232 estimated TWA concentrations from the POCIS $(n=3)$. The values of the average concentrations

233 and corresponding standard deviations are provided in the Supplemental Data, Table S3 along

234 with the concentrations measured in grab samples collected at deployment and retrieval. The

235 concentrations measured in grab samples were used only to provide a comparison point to

236 determine if POCIS was an effective monitoring technique, despite the potential for biofouling of

237 the samplers or blockage of the deployment cages. Concentrations of some analytes measured in

238 grab samples were lower than TWA concentrations estimated from POCIS, consistent with the

239 results of a study by Jones-Lepp et al. [16]. In some cases, analytes were detected or quantifiable

240 in POCIS but not in the corresponding grab samples, which illustrates the value of passive

241 sampling for concentrating trace contaminants to detectable levels, and the importance of

242 effective sampling strategies. Overall, the results are in good agreement and no significant

243 variations were observed in the grab samples collected at deployment and retrieval.

Rodayan, A., Afana, S., Segura, P.A., Sultana, T., Metcalfe, C., Yargeau, V., Linking drugs of abuse in 
244 Concentration observed in upstream samples can be explained by the presence of upstream

245 WWTPs on discharging their treated effluent in the same river.

Considering that our previous studies showed that POCIS underestimated the

248 concentrations of DOAs in untreated wastewater (Metcalfe et al., 2010), we did not deploy

249 POCIS in the untreated wastewater stream and so, did not attempt to calculate removals of DOAs

250 within the WWTP. However, our previous studies of monitoring for pharmaceuticals in DWTPs

251 using POCIS showed that this monitoring technique provides reliable estimates of time-weighted

252 average concentrations in treated and untreated drinking water that are free of the biases from

253 grab sample monitoring caused by the residence time in the DWTP (Metcalfe et al., 2014). Table

2541 presents the average removals (\%) of each compound during drinking water treatment. The

255 statistical significance of the values, identified by an asterisk, was determined using the Software

256 Prism 6 and unpaired t-tests. This small DWTP was operating above its designed capacity during

257 the sampling campaign and so therefore, cannot be considered as representative of the drinking

258 water treatment in most developed countries. However, these results indicate that, under

259 conditions of sub-optimal treatment, contamination of surface water with DOAs of wastewater

260 origin can impact the quality of treated drinking water due to low removals of these compounds.

\subsection{Cocaine, BE and sucralose}

262 Cocaine and its major metabolite BE were detected at all monitoring locations with both

263 sampling techniques (Figure 1a). These compounds were detected at the two stations upstream of

264 the WWTP discharge, which illustrates that the Grand River is impacted by discharges of CECs

265 from several upstream WWTPs. A decrease in the level of cocaine was observed between the

Rodayan, A., Afana, S., Segura, P.A., Sultana, T., Metcalfe, C., Yargeau, V., Linking drugs of abuse in wastewater to contamination of surface and drinking water, Environmental Toxicology and Chemistry, Volume 35, Issue 4, 843-849 (April 2016) 
two upstream sites. Since there was not a significant decline in the concentrations of sucralose at

267 these two upstream locations (Figure 1b), the loss of cocaine may be explained by microbial or

268 photolytic degradation of cocaine to transformation products $[15,33]$. The ratios of $\mathrm{BE}$ to

269 cocaine were approximately 1 at the two upstream locations.

The ratios of BE to cocaine in surface water were between 2.6 and 4.2 downstream of the

272 WWTP discharge (Figure 2), which is within the range of values observed by others (Van Nuijs

273 et al. 2009b). There was a trend to declining ratios of BE to cocaine with distance downstream in

274 the river for data generated from both the grab samples and the POCIS (Figure 2). Since the

275 ratios were similar for both POCIS and grab sample data, we can rule out that this trend was due

276 to preferential adsorption of one of the two compounds onto the POCIS sorbent. These ratio data

277 suggest that cocaine might be more persistent relative to BE. Since it has been shown that

278 cocaine is more susceptible to microbial degradation than BE in aqueous matrices [6, 34], it may

279 be that $\mathrm{BE}$ is lost through other fate processes, such as sorption to particulates, volatilization or

280 photodegradation. For example Bijlsma et al. [9] showed that BE is removed in WWTPs slightly

281 more efficiently than cocaine (90\% for BE compared to $79 \%$ for cocaine); possibly through

282 transport to sludge. Further studies are required to investigate the processes responsible for these

283 changes in the ratios of cocaine and BE during wastewater treatment and in natural surface

284 waters. The concentrations of BE and cocaine remained stable with distance downstream of the

285 WWTP discharge (Figure 1a). This is not consistent with the data for sucralose, which showed a

286 decline in concentrations between the first $\left(561 \mathrm{ng} \mathrm{L^{-1 }}\right)$ and second $\left(260 \mathrm{ng} \mathrm{L}^{-1}\right)$ downstream

287 sites, but then stable concentrations further downstream (Figure 1b). 
The concentrations of cocaine and BE observed in all surface water samples were lower

290 than the maximum concentrations reported in Europe. For instance, cocaine and BE were

291 detected in surface water at concentrations between 10 and $111 \mathrm{ng} \mathrm{L}^{-1}$ in Spain [35], at

292 maximum concentrations of 115 and $520 \mathrm{ng} \mathrm{L}^{-1}$, respectively in Belgium [36], and at maximum

293 concentrations of 78 to $92 \mathrm{ng} \mathrm{L}^{-1}$, respectively in south Wales [35-37]. The concentrations of

294 sucralose in the Grand River (i.e. $>100 \mathrm{ng} \mathrm{L}^{-1}$ ) are consistent with previous studies [26, 28, 38].

Considering that the concentrations of cocaine and BE (4.2 and $10 \mathrm{ng} \mathrm{L}^{-1}$, respectively) in

297 the treated drinking water were not significantly different than the influent concentrations,

298 removals in the DWTP could not be calculated. In contrast, a significant removal of 49\% was

299 found for sucralose in the DWTP (Table 1). A study conducted at a DWTP in Spain equipped

300 with chlorination, ozonation and granular activated carbon filtration reported overall removal

301 efficiencies for cocaine and BE of $100 \%$ and $89 \%$, respectively, and BE was detected in the

302 treated drinking water at mean concentrations of $45 \mathrm{ng} \mathrm{L}^{-1}$, with a maximum of $130 \mathrm{ng} \mathrm{L}^{-1}$ [35].

303 However, Boleda et al. [14] investigated tap water from DWTPs with different treatment

304 technologies in several countries and found that BE and cocaine were present in treated drinking

305 water at maximum concentrations of 15 and $2.9 \mathrm{ng} \mathrm{L}^{-1}$, respectively and that the removal of these

306 compounds is a strong function of the treatment technologies available. The DWTP monitored in

307 the present study was operating at flows close to or greater than the maximum design capacity of

308 the plant and it did not employ advanced treatment technologies, such as ozonation and activated

309 carbon filtration. Therefore, it is not surprising that removals of sucralose, cocaine and BE were

310 relatively low. In addition, van der Aa et al. [39] reported that only BE was detected in finished

Rodayan, A., Afana, S., Segura, P.A., Sultana, T., Metcalfe, C., Yargeau, V., Linking drugs of abuse in 
311 drinking water in a study preformed in the Netherlands, at a concentration below its limit of 312 detection.

\section{$314 \quad 3.3$ Amphetamines}

Amphetamine, MDA and ephedrine were detected at concentrations >LOQ in surface

316 water upstream (4 to $24 \mathrm{ng} \mathrm{L}^{-1}$ ) and downstream (6 to $49 \mathrm{ng} \mathrm{L}^{-1}$ ) of the WWTP discharge (Figure

317 1c). There is a trend of declining concentrations of ephedrine with distance downstream of the

318 WWTP discharge (Figure 1c), indicating possible degradation of these compounds in surface

319 waters or sorption to river sediments, considering that no such decline in concentration was

320 observed for sucralose. The levels of ephedrine measured in the present study are in agreement

321 with those reported by Valcárcel et al. [15], who detected ephedrine at concentrations between

3221.76 and $14.70 \mathrm{ng} \mathrm{L}^{-1}$ in a river in Spain. Postigo et al. [5] reported an ephedrine concentration of

$323145 \mathrm{ng} \mathrm{L}^{-1}$ in another river in Spain. The higher levels of ephedrine in surface water, compared to

324 other amphetamine stimulants are probably due to its widespread use as a decongestant and

325 possibly in herbal medicines, high rate of excretion of the parent compound from the human

326 body (22-99\%) and incomplete removal during wastewater treatment [5]. Amphetamine was

327 detected in surface waters at 6.8 and $3.38 \mathrm{ng} \mathrm{L}^{-1}$ in Spain (Vazquez-Roig et al. 2010), but was not

328 detected in a study in the USA [5, 40, 41], which is consistent with the data obtained in the

329 present study. MDMA and methamphetamine were not detected in treated wastewater and in

330 surface water in the present study, which may be due to low usage of Ecstasy as an illicit drug in

331 this urban area. 
For samples collected at the DWTP, amphetamine, methamphetamine and MDMA were

334 not detected in any samples (untreated or treated). MDA and ephedrine were detected above their

335 respective LOQs. Removals from drinking water during treatment could not be estimated

336 because there was no significant difference in the concentrations in raw and treated drinking

337 water. Few studies have investigated the presence of amphetamine stimulants in drinking water,

338 but one study conducted in Europe showed that all amphetamines studied were completely

339 removed during drinking water treatment [35].

3413.4 Opioids

Methadone was not present at concentrations $>$ LOQs in any samples and therefore, this compound was not included in Figure 1d. Heroin was not detected at concentrations above either

344 its LOQ or LOD. As we previously did not detect heroin in 24-h composite samples from two

345 WWTPs in Canada [22], it is likely that the results are not due to low uptake by the passive

346 samplers, but rather due to a rapid rate of transformation. Low concentrations of this compound

347 may be explained by its biotransformation to 6-acetylmorphone and morphine [42].

Fentanyl was detected in all samples (Figure 1d), despite its high excretion in humans as

350 norfentanyl (26-55\%) and its tendency to partition into the sludge phase $[4,43]$. The low

351 concentration of oxycodone and the high levels of fentanyl and ketamine in wastewater are

352 significant from the perspective of drug abuse in the province of Ontario, Canada. The

353 Oxycontin ${ }^{\circledR}$ formulation of oxycodone was banned in Ontario in 2012 because of concerns that

354 this form of the drug, which can be easily crushed and dissolved in water for intravenous 
355 injection, was contributing to high overdose deaths from abuse of this prescription pain killer

356 [44]. Subsequent to this ban, drug enforcement agencies in Ontario reported an increase in the

357 use of ketamine and fentanyl, and indeed there has been a rise in deaths as a result of fentanyl

358 overdoses, as reported in 2012 by the Office of the Coroner for Ontario.

The concentrations of the opioid target compounds in surface water did not show any clear

361 patterns between sampling points (Figure 1d). The concentrations of fentanyl, codeine and

362 ketamine decreased downstream of the WWTP discharge, while the concentrations of morphine,

363 acetylmorphine, acetylcodeine, dihydrocodeine, tramadol and oxycodone did not show any clear

364 trends. These data may indicate that the latter compounds are not rapidly degraded in surface

365 water. Of particular interest are the data for tramadol, which showed declining concentrations in

366 surface water downstream of the WWTP discharge (Figure 1d). This was also observed in a

367 study conducted in German surface waters where levels of tramadol were $<25$ to $381 \mathrm{ng} \mathrm{L}^{-1}$ and

368 declined with distance from the WWTP discharge [45]. Indirect photodegradation has been

369 shown to be the main process responsible for the removal of tramadol in surface water under

370 ambient conditions [46]. EDDP was not detected in any surface water samples in the present

371 study, although these compounds have been detected in river water samples in other studies [2,

$37215]$.

Several of the opioids were not detected, or were detected at concentrations below the

375 LOQ in the untreated and treated drinking water. Removals could not be calculated for these

376 compounds, including amphetamine, methamphetamine, MDMA, methadone and EDDP. 
377 Several other opioids were detected in POCIS deployed in both untreated and treated drinking

378 water, including fentanyl, ketamine, oxycodone, tramadol, morphine and codeine and

379 dihydrocodeine. Using the POCIS data, removals could be calculated for compounds where there

380 were statistically significant differences in the TWA concentrations in raw and treated drinking

381 water; specifically for codeine (25\%) and ketamine (49\%). In studies conducted in Europe on

382 opioids in drinking water, only methadone and EDDP were detected at concentrations $>$ LOQs [2,

383 14]. The high number of opioid compounds detected in the current studies using POCIS

384 demonstrates the value of using passive sampling techniques to monitor for trace quantities of

385 CECs in drinking water.

\section{CONCLUSIONS}

The results of the present study demonstrate for the first time that drugs of abuse are

390 present in Canadian surface waters impacted by wastewater discharges. The data also provide

391 evidence that there is downstream transport of these compounds, such that wastewater discharges

392 into surface waters have the potential to contaminate downstream sources of drinking water with

393 drugs of abuse; albeit at relatively low concentrations.

Analysis of surface water samples indicated that the concentrations of cocaine, BE,

396 morphine, acetylmorphine, dihydrocodeine and acetylcodeine and oxycodone did not decline in

397 the Grand River with distance downstream from the WWTP discharge, which was consistent

398 with the persistence of sucralose in the watershed. Overall, we accept our original hypothesis that 
399 at least some of these DOAs are persistent in aquatic systems and surface water contamination

400 associated with wastewater discharges may impact the quality of drinking water in urban

401 watersheds.

Figure S1. Comparison of estimated and measured amounts of the target compounds retained by the POCIS sorbent

Table S1. Chemical formulae, corresponding deuterated analogs, SPE recoveries, POCIS extraction efficiencies and POCIS sampling rates of target compounds

Table S2. Limits of detection (LODs) and limits of quantification (LOQs) in wastewater, surface

408 water and drinking water

409 Table S3. Mean concentration $(\mathrm{n}=3, \pm \mathrm{SD})$ in $\mathrm{ngL}^{-1}$ estimated from amounts accumulated in 410 POCIS, or determined from analysis of grab samples collected at the time of deployment and 411 retrieval of the POCIS, respectively.

\section{ACKNOWLEDGEMENTS}

We gratefully acknowledge the assistance of the staff at the wastewater and drinking water treatment plants for aid in collecting the samples. We also acknowledge the help of G. Tetreault

416 from the University of Waterloo for field work assistance and B. McIlwain of Trent University

417 for her help with sample preparation. This work was supported by the Natural Sciences and

418 Engineering Council (NSERC) of Canada through a Strategic Grant (PI: V. Yargeau) and the

Rodayan, A., Afana, S., Segura, P.A., Sultana, T., Metcalfe, C., Yargeau, V., Linking drugs of abuse in 
420 sweeteners (PI: C. Metcalfe). We also thank NSERC, Fonds québécois de la recherche sur la

421 nature et les technologies (FRQ-NT) and the Eugenie Ulmer Lamothe Fund scholarships

422 awarded to A. Rodayan, P.A. Segura and S. Afana.

\section{REFERENCES}

424 1. Daughton, CG, 2011. Illicit drugs: Contaminants in the environment and utility in forensic epidemiology. Rev Environ Contam T, 210: p. 59-110.

2. Boleda, MR, MT Galceran, and F Ventura, 2009. Monitoring of opiates, cannabinoids and their metabolites in wastewater, surface water and finished water in catalonia, spain. Water Res, 43(4): p. 1126-1136.

4. Huerta-Fontela, M, MT Galceran, J Martin-Alonso, and F Ventura, 2008a. Occurrence of

3. Chiaia, AC, C Banta-Green, and J Field, 2008. Eliminating solid phase extraction with large-volume injection lc/ms/ms: Analysis of illicit and legal drugs and human urine indicators in us wastewaters. Environ Sci Technol, 42: p. 8841-8848. psychoactive stimulatory drugs in wastewaters in north-eastern spain. Sci Total Environ, 397(1-3): p. 31-40.

5. Postigo, C, MJ Lopez de Alda, and D Barcelo, 2010. Drugs of abuse and their metabolites in the ebro river basin: Occurrence in sewage and surface water, sewage treatment plants removal efficiency, and collective drug usage estimation. Environ Pollut, 36(1): p. 75-84. 6. Zuccato, E, S Castiglioni, R Bagnati, C Chiabrando, P brassi, and R Fanelli, 2008. Illicit
drugs, a novel group of environmental contaminants. Water Res, 42: p. 961-968.

7. Loganathan, B, M Phillips, H Mowery, and TL Jones-Lepp, 2009. Contamination profiles and mass loadings of macrolide antibiotics and illicit drugs from a small urban wastewater treatment plant. Chemosphere, 75(1): p. 70-77.

8. Terzic, S, I Senta, and M Ahel, 2010. Illicit drugs in wastewater of the city of zagreb (croatia) - estimation of drug abuse in a transition country. Environmental Pollution, 158(8): p. 2686-2693.

9. Bijlsma, L, E Emke, F Hernández, and P de Voogt, 2012. Investigation of drugs of abuse and relevant metabolites in dutch sewage water by liquid chromatography coupled to high resolution mass spectrometry. Chemosphere, 89(11): p. 1399-1406.

10. Brodin, T, J Fick, M Jonsson, and J Klaminder, 2013. Dilute concentrations of a psychiatric drug alter behavior of fish from natural populations. Science, 339(6121): p. 814-815.

Rodayan, A., Afana, S., Segura, P.A., Sultana, T., Metcalfe, C., Yargeau, V., Linking drugs of abuse in wastewater to contamination of surface and drinking water, Environmental Toxicology and Chemistry, Volume 35, Issue 4, 843-849 (April 2016) 
11. De Lange, HJ, W Noordoven, AJ Murk, M Lürling, and ETHM Peeters, 2006. Behavioural responses of gammarus pulex (crustacea, amphipoda) to low concentrations of pharmaceuticals. Aquatic Toxicology, 78(3): p. 209-216.

12. Castiglioni, S, R Bagnati, R Fanelli, F Pomati, D Calamari, and E Zuccato, 2006. Removal of pharmaceuticals in sewage treatment plants in italy. Environ Sci Technol, 40: p. 357-363.

13. Tixier, C, HP Singer, S Oellers, and SR Müller, 2003. Occurrence and fate of carbamazepine, clofibric acid, diclofenac, ibuprofen, ketoprofen, and naproxen in surface waters. Environ Sci Technol, 37(6): p. 1061-1068.

14. Boleda, MR, M Huerta-Fontela, F Ventura, and MT Galceran, 2011. Evaluation of the presence of drugs of abuse in tap waters. Chemosphere, 84: p. 1601-1607.

15. Valcárcel, Y, F Martínez, S González-Alonso, Y Segura, M Catalá, R Molina, JC Montero-Rubio, N Mastroianni, M López de Alda, C Postigo, and D Barcelo, 2012. Drugs of abuse in surface and tap waters of the tagus river basin: Heterogeneous photofenton process is effective in their degradation. Environ Int, 41: p. 35-43.

16. Jones-Lepp, TL, C Sanchez, DA Alvarez, DC Wilson, and R-L Taniguchi-Fu, 2012. Point sources of emerging contaminants along the colorado river basin: Source water for the arid southwestern united states. Sci Total Environ, 430: p. 237-245.

17. Kot-Wasik, A, B Zabiegala, M Urbanowicz, E Dominiak, A Wasik, and J Namiesnik, 2007. Advances in passive sampling in environmental studies. Anal Chim Acta 602: p. 141-163.

18. Alvarez, DA, JD Petty, JN Huckins, TL Jones-Lepp, DT Getting, JP Goddard, and SE Manahan, 2004. Development of a passive, in situ, integrative sampler for hydrophilic organic contaminants in aquatic environments. Environ Toxicol Chem, 23(7): p. 16401648.

19. MacLeod, SL, EL McClure, and CS Wong, 2007. Laboratory calibration and field deployment of the polar organic chemical integrative sampler for pharmaceuticals and personal care products in wastewater and surface water. Environ Toxicol Chem, 26(12): p. 2517-2729.

20. Mazzella, N, JF Dubernet, and F Delmas, 2007. Determination of kinetic and equilibrium regimes in the operation of polar organic chemicals integrative samplers - application to the passive sampling of the polar hebicides in aquatic environments. J Chromatogr A, 1154: p. 42-51.

21. Harman, C, M Reid, and KV Thomas, 2011. In situ calibration of a passive sampling device for selected illicit drugs and their metabolites in wastewater, and subsequent yearlong assessment of community drug usage. Environ Sci Technol, 45(13): p. 5676-5682.

22. Yargeau, V, B Taylor, H Li, A Rodayan, and CD Metcalfe, 2014. Analysis of drugs of abuse in wastewater from two canadian cities. Sci Total Environ, 487: p. 722-730.

23. Jones-Lepp, TL, DA Alvarez, JD Petty, and JN Huckins, 2004. Polar organic chemical integrative sampling and liquid chromatography-electrospray/ion-trap mass spectrometry

Rodayan, A., Afana, S., Segura, P.A., Sultana, T., Metcalfe, C., Yargeau, V., Linking drugs of abuse in wastewater to contamination of surface and drinking water, Environmental Toxicology and Chemistry, Volume 35, Issue 4, 843-849 (April 2016) 
for assessing selected prescription and illicit drugs in treated sewage effluents. Arch Environ Contam Toxicol, 47(4): p. 427-39.

24. Servos, M, M Smith, R McInnis, K Burnison, B-H Lee, and P Seto, 2007. The presence of selected pharmaceuticals and personal care products in drinking water in ontario, canada. Wat Qual Res J Canada, 42(2): p. 130-137.

25. Metcalfe, C, K Tindale, H Li, A Rodayan, and V Yargeau, 2010. Illicit drugs in canadian municipal wastewater and estimates of community drug use. Environ Pollut, 158: p.

26. Scheurer, M, H-J Brauch, and F Lange, 2009. Analysis and occurrence of seven artificial sweeteners in german waste water and surface water and in soil aquifer treatment (sat). Analytical and Bioanalytical Chemistry, 394(6): p. 1585-1594.

27. Mawhinney, DB, RB Young, BJ Vanderford, T Borch, and SA Snyder, 2011. Artificial sweetener sucralose in u.S. Drinking water systems. Environmental Science \& Technology, 45(20): p. 8716-8722.

28. Spoelstra, J, S Schiff, and S Brown, 2013. Artificial sweeteners in a large canadian river reflect human consumption in the watershed. PLoS ONE, 8(12).

29. Li, H, PA Helm, and C Metcalfe, 2010. Sampling in the great lakes for pharmaceuticals, personal care products and endocrine disrupting substances using the passive polar organic chemical integrative sampler. Environ Toxicol Chem, 29(4): p. 751-762.

30. Metcalfe, C, M Hoque, T Sultana, C Murray, P Helm, and S Kleywegt, 2014. Monitoring for contaminants of emerging concern using pocis passive samplers in drinking water from ontario, canada. Environ Sci: Processes \& Impacts, Accepted.

31. Li, H, PA Helm, and CD Metcalfe, 2010. Sampling in the great lakes for pharmaceuticals, personal care products, and endocrine-disrupting substances using the passive polar organic chemical integrative sampler. Environmental Toxicology and Chemistry, 29(4): p. 751-762.

32. Allan, IJ, J Knutsson, N Guigues, GA Mills, AM Fouillac, and R Greenwood, 2208. Chemcatcher and dgt passive sampling devices for regulatory monitoring of trace metals in surface water. Journal of Environmental Monitoring, 10: p. 821-829.

33. Gheorghe, A, A van Nuijs, B Pecceu, L Bervoets, PG Jorens, R Blust, H Neels, and A Covaci, 2008. Analysis of cocaine and its principal metabolites in waste and surface water using solid-phase extraction and liquid chromatography-ion trap tandem mass spectrometry. Anal Bioanal Chem, 391: p. 1309-1319.

34. Van Nuijs, ALN, B Pecceu, L Theunis, N Dubois, C Charlier, PG Jorens, L Bervoets, R Blust, H Meulemans, H Neels, and A Covaci, 2009. Can cocaine use be evaluated through analysis of wastewater? A nation-wide approach conducted in belgium. Addiction, 104(5): p. 734-741.

35. Huerta-Fontela, M, MT Galceran, and F Ventura, 2008b. Stimulatory drugs of abuse in surface waters and their removal in a conventional drinking water treatment plant. Environ Sci Technol, 42(18): p. 6809-6816.

Rodayan, A., Afana, S., Segura, P.A., Sultana, T., Metcalfe, C., Yargeau, V., Linking drugs of abuse in wastewater to contamination of surface and drinking water, Environmental Toxicology and Chemistry, Volume 35, Issue 4, 843-849 (April 2016) 
36. Van Nuijs, ALN, B Pecceu, L Theunis, N Dubois, C Charlier, PG Jorens, L Bervoets, R Blust, H Neels, and A Covaci, 2009. Cocaine and metabolites in waste and surface water across belgium. Environ Pollut, 157: p. 123-129.

37. Kasprzyk-Hordern, B, RM Dinsdale, and AJ Guwy, 2008. Multiresidue methods for the analysis of pharmaceuticals, personal care products and illicit drugs in surface water and wastewater by solid-phase extraction and ultra performance liquid chromatographyelectrospray tandem mass spectrometry. Anal Bioanal Chem, 39: p. 1293-1308.

38. Loos, R, BM Gawlik, K Boettcher, G Locoro, S Contini, and G Bidoglio, 2009. Sucralose screening in european surface waters using a solid-phase extraction-liquid chromatography-triple quadrupole mass spectrometry method. J. Chromatogr. A, 1216(7): p. 1126-1131.

39. van der Aa, M, L Bijlsma, E Emke, E Dijkman, ALN van Nuijs, B van de Ven, F Hernández, A Versteegh, and P de Voogt, 2013. Risk assessment for drugs of abuse in the dutch watercycle. Water Research, 47(5): p. 1848-1857.

40. Bartelt-Hunt, SL, DD Snow, T Damon, J Shockley, and K Hoagland, 2009. The occurrence of illicit and therapeutic pharmaceuticals in wastewater effluent and surface waters in nebraska. Environ Pollut, 157(3): p. 786-791.

41. Vazquez-Roig, P, V Andreu, C Blasco, and Y Picó, 2010. Spe and lc-ms/ms determination of 14 illicit drugs in surface waters from the natural park of l'albufera (valència, spain). Anal Bioanal Chem, 397(7): p. 2851-2864.

42. Trescot, AM, S Datta, M Lee, and H Hansen, 2008. Opioid pharmacology. Pain Physician 2008: Opioid Special Issue, (11): p. S133-S153.

43. Baselt, RC, Disposition of toxic drugs and chemicals in man. 3rd ed. 2004, Foster City, CA: Biomedical Publications.

44. Fischer, B, N Nakamura, B Rush, J Rehm, and K Urbanoski, 2010. Changes in and characteristics of admissions to treatment related to problematic prescription opioid use in ontario, 2004-2009. Drug and Alcohol Dependence, 109(1-3): p. 257-260.

45. Rua-Gomez, PC and W Puttmann, 2012. Impact of wastewater treatment plant discharge of lidocaine, tramadol, venlafaxine and their metabolites on the quality of surface waters and groundwater. J Environ Monitor, 14(5): p. 1391-1399.

46. Rúa-Gómez, PC and W Püttmann, 2013. Degradation of lidocaine, tramadol, venlafaxine and the metabolites o-desmethyltramadol and o-desmethylvenlafaxine in surface waters. Chemosphere, 90(6): p. 1952-1959. 


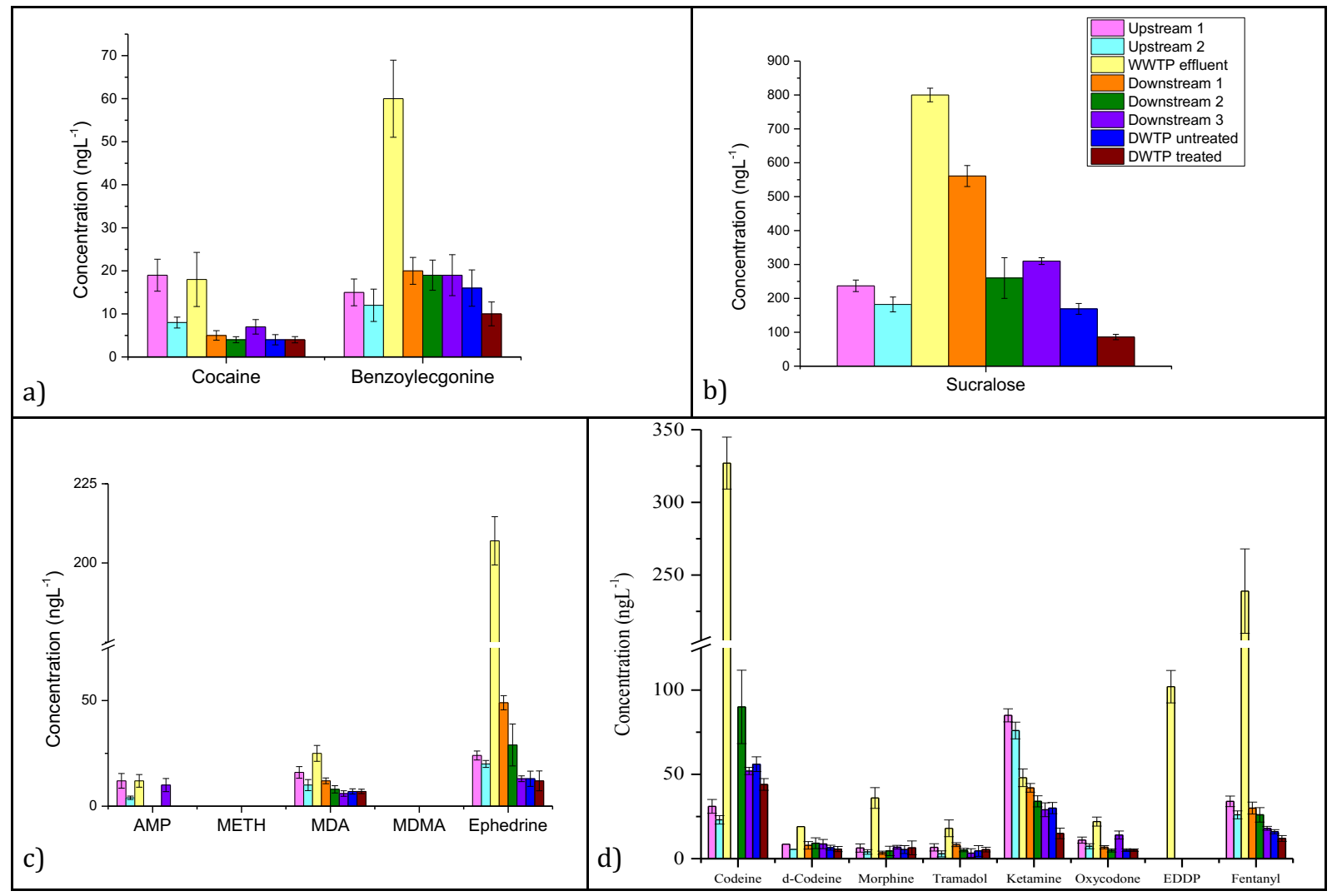

Figure 1. Average trends of concentrations of (a) cocaine and benzoylecgonine, (b) sucralose, (c) amphetamine-type stimulants and (d) other DOAs, in the Grand River, at the WWTP and DWTP (error bars represent one standard deviation). d-Codeine $=$ dihydrocodeine. Heroin, acetylcodeine and acetylmorphine are not included since no sampling rate was available. Methadone is not included since it was not detected in any sample. 


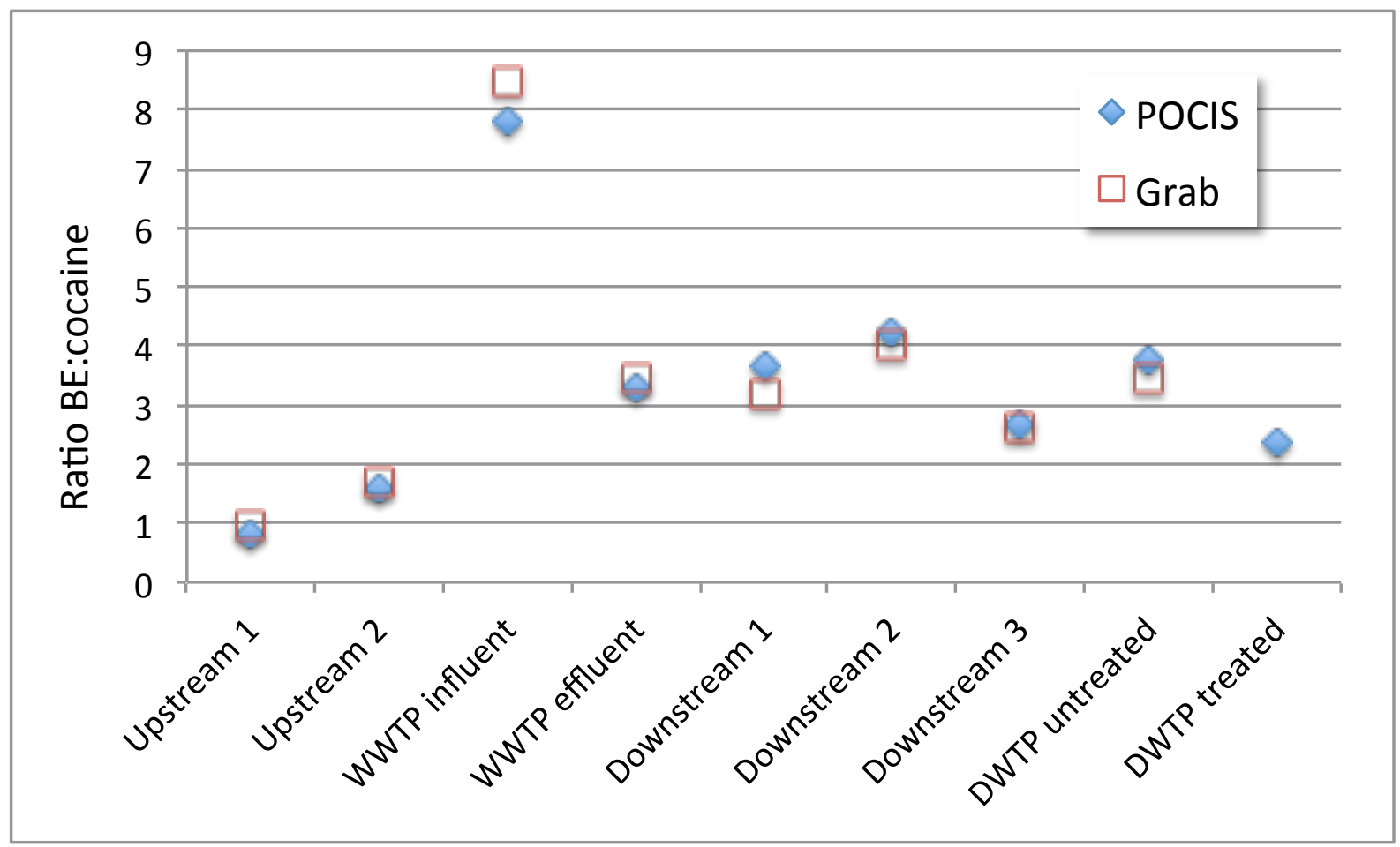

572 Figure 2. Ratio of average benzoylecgonine (BE) concentration to average cocaine concentration at a given sample location in POCIS and grab samples (each data point represents the average concentration of $n=3$ for POCIS and $n=6$ for grab). 
576 Table 1. Mean removal efficiencies of analytes at the DWTP $(n=3)$

\begin{tabular}{|c|c|}
\hline Compounds & $\begin{array}{c}\text { DWTP } \\
\text { Removal } \\
\text { Efficiencies }\end{array}$ \\
\hline
\end{tabular}

\begin{tabular}{|c|c|}
\hline \multicolumn{2}{|c|}{ Cocaine \& its metabolite } \\
\hline Cocaine & -18 \\
\hline Benzoylecgonine & 14 \\
\hline Sucralose & $\mathbf{4 9}^{*}$ \\
\hline
\end{tabular}

\section{Amphetamine-type stimulants}

\begin{tabular}{|c|c|}
\hline Amphetamine & $<$ LOQ \\
\hline Methamphetamine & $<$ LOQ \\
\hline MDA & 7 \\
\hline MDMA & $<$ LOQ \\
\hline Ephedrine & 10 \\
\hline
\end{tabular}

\begin{tabular}{|c|c|}
\hline Opioids & $\mathbf{2 5}$ \\
\hline Codeine & NA \\
\hline Acetylcodeine & -10 \\
\hline Dihydrocodeine & -2 \\
\hline Morphine & NA \\
\hline Acetylmorphine & $<$ LOQ \\
\hline Methadone & NA \\
\hline Heroin & -39 \\
\hline Tramadol & $\mathbf{4 9 *}$ \\
\hline Ketamine & -3 \\
\hline Oxycodone & $<$ LOQ \\
\hline EDDP & 0 \\
\hline Fentanyl
\end{tabular}

$577<$ LOQ Removal level not calculated due to concentrations $<$ LOQ

578 NA Removal level not calculated due to unavailable sampling rates

$579 * \quad$ Statistically significant based on t-test $(\mathrm{p}<0.05)$ 